\title{
Tensões do SAEB e do IDEB para a educação de qualidade como direito
}

\author{
Liliane Ribeiro de Mello \\ Regiane Helena Bertagna \\ Universidade Estadual Paulista (Brasil)
}

\section{Resumo}

A avaliação da educação básica no Brasil tem uma trajetória histórica já consolidada, a qual sempre se pontuou a articulação com a busca do poder público pela melhoria da qualidade. Este artigo tem por objetivo destacar as políticas de avaliação externa nacional, analisando o Sistema de Avaliação Nacional da Educação Básica (SAEB) e o Índice de Desenvolvimento da Educação Básica (IDEB), para deflagrar a concepção de qualidade educacional subjacente a estas políticas e problematizar a garantia do direito à educação pública de qualidade. Foi realizada uma pesquisa qualitativa a partir de levantamento e análise documental das portarias e relatórios do Ministério da Educação (MEC) e do Instituto Nacional de Estudos e Pesquisas Educacionais Anísio Teixeira (INEP), em diálogo com referencial teórico. A partir da análise, consideramos que o SAEB e IDEB apresentam limites em suas configurações para abarcar a garantia do direito à educação pública de qualidade.

Palavras-chave: Avaliação educacional. SAEB. IDEB. Qualidade educacional.

\section{Tensions of SAEB and IDEB for quality education as a social right}

\section{Abstract}

Basic education assessment in Brazil has a consolidated historical pathway, which always pointed out joint efforts with public authorities in the search for quality improvement. This paper aims to highlight national policies for external-assessments, analyzing the 'Sistema de Avaliação Nacional da Educação Básica - SAEB' (National Assessment System for Basic Education) and the 'Índice de Desenvolvimento da Educação Básica - IDEB' (Basic Education Development Index) to link the concept of educational quality underlying these policies and also to bring out the problems on the protection of the rights to quality public education. A qualitative research was conducted, based on document analysis of legal ordinances and technical reports issued by the 'Ministério da Educação - MEC' (Ministry of Education) and the 'Instituto Nacional de Estudos e Pesquisas Educacionais Anísio Teixeira - INEP' (Anísio Teixeira National Institute of Educational Studies and Research), in comparison with a theoretical framework. Based on this analysis we consider that SAEB and IDEB shows limitations in its configuration to assure the protection of the rights to quality public education.

Keywords: Educational assessment. SAEB. IDEB. Educational quality. 


\section{Tensiones de SAEB e IDEB para la educación de calidad como derecho}

\section{Resumen}

La evaluación de la educación básica en Brasil tiene una trayectoria histórica ya consolidada, que siempre ha estado marcada por la búsqueda del poder público en mejorar la calidad. El presente artículo tiene como objetivo destacar las políticas nacionales de evaluación externa, analizando el Sistema Nacional de Evaluación de la Educación Básica (SAEB) y el Índice de Desarrollo de la Educación Básica (IDEB), para mostrar la concepción de la calidad educativa subyacente a estas políticas y problematizar la garantía del derecho a la educación pública de calidad. Se realizó una investigación cualitativa basada en levantamiento y análisis documental de las ordenanzas e informes del Ministerio de Educación (MEC) y del Instituto Nacional de Estudios e Investigación Educativa Anísio Teixeira (INEP), en diálogo con un marco teórico. Del análisis, consideramos que SAEB e IDEB tienen límites en sus configuraciones para la garantía del derecho a la educación pública de calidad.

Palabras clave: Evaluación educativa. SAEB. IDEB. Calidad educativa.

\section{Introdução}

A educação básica pública brasileira é direito de todos (BRASIL, 1988; 1996) e é oferecida e organizada de forma descentralizada sob responsabilidade das esferas administrativas federal, estaduais e municipais em regime de colaboração, conforme art. $8^{\circ}$ da Lei n 9394/1996, Lei de Diretrizes e Bases da Educação Nacional (LDB) (BRASIL, 1996). A referida lei estipula, em seu art. $9^{\circ}$, que cabe à União (esfera federal): " $\mathrm{VI}$ - assegurar processo nacional de avaliação do rendimento escolar no ensino fundamental, médio e superior, em colaboração com os sistemas de ensino, objetivando a definição de prioridades e a melhoria da qualidade do ensino [...];" (BRASIL, 1996, s.p.), tendo em vista que essa mesma lei apresenta a garantia de padrão de qualidade como um dos princípios consagrados para o ensino.

O presente artigo tem por objetivo destacar as políticas de avaliação externa nacional, analisando o Sistema de Avaliação Nacional da Educação Básica (SAEB) e o Índice de Desenvolvimento da Educação Básica (IDEB) para deflagrar a concepção de qualidade educacional subjacente a essas políticas e problematizar a garantia do direito à educação pública de qualidade.

A avaliação da educação básica no Brasil tem uma trajetória histórica já consolidada que sempre se pontuou pela articulação do poder público em 
busca da qualidade, como se pode constar no documento de apresentação do SAEB 2019:

Sistema de Avaliação da Educação Básica (Saeb) tem como objetivo diagnosticar a educação básica do País e contribuir para a melhoria de sua qualidade, oferecendo subsídios concretos para a formulação, a reformulação e o monitoramento das políticas públicas voltadas para a educação básica. IINSTITUTO NACIONAL DE ESTUDOS E PESQUISAS EDUCACIONAIS ANÍSIO TEIXEIRA, 2019, p. 4, grifos nossos).

Destarte, embora saibamos da vastidão de modelos avaliativos externos nas esferas estaduais e municipais (BROOKE; CUNHA; FALEIROS, 2012; BAUER; SOUZA; HORTA NETO; VALE; PIMENTA, 2017; BERTAGNA; BORGHI, 2018 ), enfocamos na proposta avaliativa nacional organizada pela administração federal que, além de ser essa a sua função, como propõe a legislação, abrange todos os demais sistemas de ensino. Trata-se, então, de analisar o SAEB e o IDEB como políticas oficiais para avaliação da educação nacional.

A pesquisa qualitativa realizada a partir de levantamento e análise documental das portarias e relatórios do Ministério da Educação (MEC) e do Instituto Nacional de Estudos e Pesquisas Educacionais Anísio Teixeira (INEP), em diálogo com referencial teórico, possibilitou verificar as características das avaliações e a contextualização histórica para, então, refletirmos sobre as concepções de qualidade.

artigo está organizado em três partes: a) apresentação das políticas de avaliação externa nacional, SAEB e IDEB com seu histórico e suas características; b) análise das concepções de qualidade considerando a difundida pelo Estado brasileiro (oficial) e as discussões teóricas sobre a polissemia do conceito, além da defesa da ampliação das dimensões avaliadas, considerando o princípio da formação humana; c) apontamentos finais problematizando as políticas de avaliação para garantia do direito à educação pública de qualidade. 


\section{Tateando a trajetória da avalição nacional da educação básica}

A avaliação de sistemas tem por objetivo verificar aspectos globais das redes de ensino para acompanhamento dos desempenhos dos sistemas e orientação de políticas públicas (FREITAS; SORDI; MALAVASI; FREITAS, 2012). Para isso, requer a coleta de dados sobre diversas dimensões do sistema de ensino, como os referentes a acesso, permanência, infraestrutura das escolas, financiamento, valorização do magistério, gestão democrática, aprendizagens e valores formativos, bem como fatores do entorno escolar.

As experiências mais difundidas para monitorar o sistema educacional têm como principal foco o instrumento dos testes cognitivos, para verificar o rendimento escolar dos alunos. $\bigcirc$ uso dos testes objetivos como instrumentos avaliativos tiveram base nos estudos estadunidenses na década de 1960, como o de Bloom (1972), com a taxionomia de objetivos educacionais que buscava uma organização hierárquica de objetivos educacionais, no entanto, sofreu grandes distorções na prática.

Assim como Raphael (1995), entendemos que todo procedimento técnico traz consigo a questão política da avaliação.

A solução técnica usa o aparato científico para se chegar à verdade e à solução de problemas. Esta obsessão por procedimentos racionais muitas vezes esconde o sentido real do problema, por ignorar um aspecto políitico, muitas vezes calcado em ideologias dominantes do senso comum ou da classe social hegemônica (RAPHAEL, 1995, p. 40).

Dias Sobrinho (2004), ao tratar da epistemologia objetivista em educação com racionalidade instrumental, sustenta que: "Os testes, as escalas, as estatísticas e os rankings são recursos privilegiados para verificar, controlar e produzir eficiência e qualidade, mas segundo noções de eficiência e qualidade que correspondam a essa racionalidade" (DIAS SOBRINHO, 2004, p. 712).

A implementação das avaliações padronizadas do sistema de ensino em larga escala alcança o campo internacional. Atribuímos a este processo às reformas políticas que têm ocorrido e que, numa perspectiva neoliberal, se mostram eficazes para adequação do ensino aos padrões produtivistas. Essas reformas têm se tornado instrumento do gerencialismo na esfera pública, com 
modelos de certa forma globalizados, para medir a eficiência e a eficácia do sistema de ensino, muitas vezes, com parâmetros de mercado.

Evidenciamos a influência de organismos internacionais para reformulações das políticas educacionais. $\bigcirc$ Banco Mundial (BM), por exemplo, tem disseminado, através de seus relatórios, a ideia de que é necessário minimizar custos e aprimorar os resultados, propagando a visão neoliberal de que o gasto com educação não é tão essencial quanto um bom "gerenciamento" desses recursos.

problema aqui, em relação às políticas públicas, é que não tem sido evidente que o uso de dados promova mudanças estruturais no desenvolvimento dos sistemas de ensino, apesar de serem capazes de obter muitas informações com instrumentos cada vez mais calibrados e abrangentes. Isso leva a administração pública a perder tempo e dinheiro, uma vez que, mesmo que importante, a simples obtenção de dados não basta. Além disso, faltam análises qualitativas, já que nem tudo em educação é passível de se contar, como afirmam Lima (1997) e Afonso (2009) ao considerar a crítica à perspectiva de educação contábil.

Encontramos as características da proposta avaliativa do sistema educacional que aqui apresentamos a partir de leituras e análises de documentos encontrados em sítio eletrônico dos órgãos responsáveis pela organização e aplicação da avaliação de sistema do Instituto Nacional de Estudos e Pesquisas Educacionais Anísio Teixeira (INEP) e do Ministério da Educação (MEC).

$\bigcirc$ primeiro marco de avaliação em larga escala no Brasil ocorreu em decorrência do compromisso entre o governo federal brasileiro e o Banco Internacional de Reconstrução e Desenvolvimento (BIRD) que, por meio do Decreto n 85.287/1980, criou o Programa de Expansão e Melhoria da Educação no Meio Rural do Nordeste - EDURURAL-NE. Como desdobramento, surgiu o Projeto Nordeste, organizado pela Secretaria Nacional de Educação Básica (SENEB) do MEC e pelo Instituto Interamericano de Cooperação para a Agricultura (IICA), em parceria com o Banco Mundial.

Enquanto o Banco Mundial previa a avaliação focada no projeto, as autoridades do MEC começaram a formulação de uma proposta que abrangesse todo o país. Em 1987, iniciaram os estudos do INEP/MEC em convênio com a Fundação Carlos Chagas para avaliar outros estados brasileiros. Criou-se, então, o projeto Avaliação do Rendimento de Alunos de Escolas de 
Tensões do SAEB e do IDEB para a educação de qualidade como direito

$1^{\circ}$ Grau da Rede Pública, com a realização de um estudo em 15 capitais e 24 cidades, tendo à frente Heraldo Marelim Vianna. Essa avaliação incluía testes de desempenho em leitura e matemática e questionários contextuais destinados às equipes gestoras, professores e famílias (VIANNA, 1988).

Freitas (2004) aponta que o marco normativo para implementação de políticas avaliativas nacionais relaciona-se também com a promulgação da Constituição Federal de 1988 (CF/88), que suscita a preocupação do Estado com a qualidade do ensino, uma vez que os artigos 206 e 214 da referida CF mencionam, respectivamente, a garantia e o desenvolvimento da qualidade do ensino como princípio e objetivo.

Em 1991, foi lançado o primeiro relatório preliminar sobre esse processo avaliativo (IICASENEB/MEC-PNUD, 1991), que passou, a partir de então, a ser denominado Sistema Nacional de Avaliação da Educação Básica (SAEB). Em 1992, lançou-se o relatório geral, apontando que em média os desempenhos dos estudantes equivaliam a menos da metade $(46,77 \%)$ dos conteúdos mínimos necessários nas áreas avaliadas e, ainda, constavam muitos problemas internos (recursos, formação docente, materiais, taxas de reprovação, evasão etc.) e externos (acesso a bens materiais, culturais, condi-

6 ção familiar etc.) aos sistemas de ensino.

Em 1992, O INEP assumiu a responsabilidade de coordenar e administrar o desenvolvimento do sistema avaliativo, assim, recuperou e ampliou sua infraestrutura estabelecida em 1988 para dar suporte à aplicação e ao processo de análises dos resultados, bem como aperfeiçoar sua metodologia. Iniciava-se, então, um processo de institucionalização da avaliação do sistema educativo no Brasil.

Notamos que esse modelo inicial abrangeu muitos eixos e dimensões para a avaliação da educação brasileira, no entanto, enquanto "[...] os estudos apontavam para as implicações educacionais e sociais da avaliação, o poder público recorria à testagem do rendimento do aluno, sendo este tomado como expressão do desempenho de escolas e sistemas " (FREITAS, 2004, p. 666). Ou seja, começou-se a estabelecer formatos de avaliação focalizados em desempenho dos estudantes.

Esse modo de formatar e gerir a avaliação do sistema de ensino brasileiro estava atrelado ao contexto de reforma administrativa do Estado e foi subsidiado por pressões de organismos internacionais (FREITAS, 2004), levando 
a uma regulação centralizada da educação básica a partir da gerência de resultados com aparatos técnicos.

A edição do Saeb do ano de 1995 foi reformulada e adotou-se a Teoria de Resposta ao Item (TRI) para construção dos testes e análise de resultados. Essa mudança na metodologia para o TRI leva à elaboração (não simples) da questão para compreender cada avanço do desempenho dos alunos buscando novas formas de avaliá-los.

público alvo foi alterado para as séries que correspondiam ao final de etapas de escolarização com testes aplicados em estudantes matriculados nas $4^{a}$ e $8^{a}$ séries do ensino fundamental lque correspondem ao $5^{\circ}$ e $9^{\circ}$ anos atualmente). Em seguida, incorporou-se o ensino médio na amostra - alunos das $2^{a}$ e $3^{a}$ séries de escolas da rede pública e da rede privada de ensino. Manteve-se a aplicação de questionários contextuais, destinados aos alunos e às suas famílias, aos professores, diretores de escolas e, também, aos aplicadores da avaliação, externos à comunidade escolar, para computar informações de condições da escola.

Foi a partir desse período, no governo do Partido da Social Democracia Brasileira (PSDB), de 1995 a 2002, com Fernando Henrique Cardoso na presidência, que prevaleceu a perspectiva de importância do rendimento escolar, com a testagem de desempenhos nas áreas de linguagem e matemática, para avaliar os sistemas, o que conota uma opção política, como bem esclarece Freitas (2004; 2007). O procedimento esteve no bojo da reforma administrativa e gerencial do Estado brasileiro, estabelecida entre 1995-1998, com processos de descentralização do sistema educativo e cobrança de resultados.

A reforma do aparelho do Estado repercutiu também em uma nova organização do MEC, que tinha como ministro Paulo Renato Souza, ex-gerente de operações do Banco Interamericano de Desenvolvimento (BID) em todo o período do governo. Essa reorganização, propiciada pelo Decreto $n^{\circ} 1.917 / 1996$ (BRASIL, 1996), permitiu que fosse criada a Secretaria de Avaliação e Informação Educacional (SEDIAE), vinculada à SEEC, que fazia parte do processo de institucionalização das avaliações educativas com a competência de planejar, orientar e coordenar o desenvolvimento de sistemas de avaliação educacional; subsidiar a formulação de políticas de monitoramento; realizar diagnósticos e articular-se com instituições nacionais e internacionais para cooperação. 
Outro marco normativo para a educação brasileira foi a aprovação da Lei n 9394/96, a Lei de Diretrizes e Bases Nacional (LDB/96), que, como destacado no início deste artigo, estabelece a incumbência da União em avaliar o rendimento escolar.

Apesar de algumas alterações nas edições subsequentes do SAEB, não se perdia o foco na testagem cognitiva dos estudantes. No ano de 2003, o modelo avaliativo foi alterado quando Luis Inácio Lula da Silva assumiu a presidência do governo do Partido dos Trabalhadores (PT). Mas, ao contrário do que se esperava, as mudanças na política educacional intensificaram a avaliação com a incorporação ao SAEB, em 2005, da Avaliação Nacional de Rendimento Escolar (Anresc), conhecida como Prova Brasil. A avaliação censitária incluiu o ensino fundamental e passou a abranger todas escolas ${ }^{1}$ do sistema público de ensino. Com isso, a proposta inicial por amostra passou a se denominar Avaliação Nacional da Educação Básica (Aneb), continuando a fazer parte do SAEB, com a aplicação em unidades escolares das áreas urbanas e rurais, incluindo amostras de alunos matriculados no $3^{\circ}$ ano do ensino médio.

A Prova Brasil foi apresentada com o objetivo de avaliar a qualidade 8 das escolas e os documentos subsequentes do INEP defendem o resultado por unidade e rede de ensino, além da importância desses resultados para ações de desenvolvimento da escola.

[...] o objetivo é que os resultados apresentados sejam incorporados pelos professores, diretores, gestores e pela própria sociedade, e que fomentem o debate e um trabalho pedagógico que subsidie a melhoria da qualidade educacional em todo o País (INSTITUTO NACIONAL DE ESTUDOS E PESQUISAS EDUCACIONAIS ANÍSIO TEIXEIRA, 201 1, s.p., grifos nossos).

Embora o governo federal brasileiro não realize o ranqueamento das escolas, a mídia tem sido insistente em fazê-lo e isso se associa à ênfase que o próprio governo tem dado aos resultados e à permissão de sua divulgação pública. Destarte, recai sobre a escola a responsabilização pelos resultados obtidos, sem um diagnóstico mais compreensivo dos outros fatores relativos às condições que levaram a tal situação.

Em 2007, foi lançado o Índice de Desenvolvimento da Educação Básica (IDEB), criado por Reynaldo Fernandes que presidia o INEP. Era um 
índice que se apresentava como medida de qualidade de cada escola pública e de cada rede de ensino, considerando os resultados dos estudantes na Prova Brasil e o fluxo escolar, calculado com base nas taxas de aprovação, reprovação e evasão (FERNANDES, 2007).

site do INEP apresenta o IDEB como instrumento de análise e como condutor de políticas públicas em prol da qualidade da educação (INEP, 2020). Na prática, os governos federal, estaduais, distrital e municipais têm utilizado o índice para avaliar a qualidade de unidades e redes de ensino e exigir resultados.

O Plano de Metas Compromisso Todos pela Educação, instituído pelo Decreto $n^{\circ}$ 6.094, de 24 de abril de 2007 (BRASIL, 2007), endossou o uso das metas do IDEB estipuladas para cada ente federado como medida de qualidade educacional encarando o cumprimento da evolução dos resultados como fator preponderante para distribuição de recursos financeiros.

Isso culminou em maior destaque aos resultados das avaliações em larga escala por serem considerados como indicadores de qualidade, juntamente com o fluxo escolar. Com esse objetivo, estudos apontam para a criação de avaliações em larga escala em níveis locais (nos estados e municípios) desde a década de 1990 (BROOKE; CUNHA; FALEIROS, 2012; BAUER; SOUZA; HORTO NETO; VALE; PIMENTA, 2017; BERTAGNA; BORGHI, 20181. Após a implementação do IDEB esse processo se intensificou. Bertagna e Borghi (2018) lembram que 14 dos 19 estados brasileiros implementaram sistemas próprios de avaliação depois da criação do IDEB, em 2007, e ainda observaram que 13 estados brasileiros e o Distrito Federal oferecem um bônus para os professores baseado em resultados de desempenho dos alunos. $\bigcirc$ levantamento de Baver; Souza; Horto Neto; Vale e Pimenta (2017) constatou que 1.573 municípios (28,5\% do total brasileiro) tinham seus próprios sistemas de avaliação.

Assim como Horta Neto (2013), também questionamos a necessidade do aumento de testes a serem realizados pelos estudantes diante de avaliações municipais, estaduais, nacional e internacional em um mesmo ano letivo, considerando que, apesar de oferecerem informações importantes, utilizam investimentos recorrentes com a mesma finalidade (avaliativa) ao invés de direcionar recursos financeiros para outras ações como suporte pedagógico e estrutura das escolas. 
No ano de 2013, criou-se a Avaliação Nacional de Alfabetização (ANA), que também integrou o SAEB, com foco nos estudantes matriculados no $3^{\circ}$ ano do ensino fundamental, considerado como o fim do ciclo da alfabetização, leitura, escrita e matemática. No entanto, a última aplicação da ANA foi em 2016, enquanto a Prova Brasil e o Aneb se mantiveram bianualmente.

A continuação do SAEB 2019 foi prevista pelas portarias $n^{\circ} 271$ do INEP, de março de 2019, e n 366 do MEC, de abril de 2019, assinadas pelo atual governo do presidente Jair Bolsonaro (sem partido). $\bigcirc$ que se destaca dessa edição é o proposto no art. $3^{\circ}$ que aponta para a ampliação das dimensões da qualidade da educação básica com a coleta de dados a partir de questionários aplicados a gestores de sistemas e de unidades, a professores, a famílias e a estudantes.

Art. $3^{\circ}$ Considerando a qualidade da Educação Básica como um atributo multidimensional, o SAEB toma como referência sete dimensões de qualidade da Educação Básica que se inter-relacionam para promover percursos regulares de aprendizagens com vistas à formação integral dos estudantes brasileiros:

\author{
I- Atendimento Escolar; \\ II - Ensino e Aprendizagem; \\ III - Investimento; \\ IV - Profissionais da Educação; \\ V-Gestão; \\ VI-Equidade; e \\ VII - Cidadania, Direitos Humanos e Valores (BRASIL, 2019, p. 47).
}

Apesar de abarcar o termo "multidimensional" para abordar a qualidade em seu teor, é importante destacar que será necessário verificar como serão tratados os instrumentos e a análise dos resultados e com que perspectivas serão elaborados e difundidos os relatórios. Isso somente será possível com a investigação das ações governamentais que serão tomadas após a publicação dos resultados, prevista somente para junho de 2021.

Com o exposto, sublinhamos que as políticas de avaliação nacionais no Brasil perduraram desde a sua elaboração e institucionalização na década de 1990, com evidente intensificação das avaliações padronizadas, regulagem dos instrumentos e processos de responsabilização pelos resultados. Portanto, têm cada vez mais impactado na organização dos sistemas de 
ensino locais que buscam melhorar os resultados, muitas vezes, limitando a esses resultados seus objetivos educacionais, o que permite pouco diálogo e participação da comunidade escolar para consagrar uma responsabilização bilateral (FREITAS, 2007) no caminho em busca de avanços educacionais.

\section{Qualidade(s) da educação: as implicações políticas dos conceitos relacionados à avaliação}

A polissemia do conceito de qualidade tem várias influências. Consideramos, para nossa análise, a qualidade que denominamos de oficial, ou seja, que se reporta ao conceito difundido pelas instituições da administração pública responsáveis pela educação, e a(s) qualidade(s) que tem(têm) sido debatida teoricamente nas pesquisas educacionais para refletir sobre o direito de todos à educação de qualidade.

Os relatórios da educação básica brasileira e dos resultados do SAEB, bem como as divulgações do resultado do IDEB, modulam uma ideia sobre a qualidade oficial brasileira: indicadores quantitativos de acesso, permanência e desempenho cognitivo em Língua Portuguesa e Matemática. Assim, com a regulação desta qualidade, a partir do SAEB e do IDEB, o Estado pode se esquivar da análise de fatores políticos, sociais e econômicos que atravessam os sistemas de ensino. Pode se esquivar até mesmo de promover os insumos necessários por aluno (Art. 208, inciso IX da CF/88) o que requer, por exemplo, maior investimento financeiro e melhor estrutura para as redes de ensino.

Como buscamos demonstrar, a formulação de propostas avaliativas para os sistemas de ensino traz consigo algumas orientações políticas para seu desenho com desdobramentos na formação dos estudantes, o que implica em compreender que não ocorrem por mera casualidade, mas que há tensões em jogo.

Há uma conformidade do enfoque em modelos avaliativos estandardizados, assentadas em um contexto histórico que enaltece a competição de mercado, com ideias meritocráticas, quantificação e comparação, como possibilidade de impulsionar melhorias.

Com base em estudos como os de Afonso (2007; 2009) e de Freitas (2004; 2007; 2012), pode-se notar que, apesar das avaliações em larga escala serem utilizadas como instrumentos para propagar a perspectiva 
mercadológica - com criação de um quase-mercado no âmbito educativo e inculcação dos princípios individualistas tanto para culpabilização quanto para premiações -, o que se configura na avaliação objetivista e produtivista (DIAS SOBRINHO, 2004), também podem ser reformuladas e utilizadas com base em modelos democráticos e emancipatórios, o que Dias Sobrinho (2004) aponta como uma avaliação subjetivista.

O reconhecimento da avaliação como fenômeno plurifacetado e de responsabilidade social significa também admitir a sua dimensão ética, para além de sua complexidade epistemológica. Atribuir valor absoluto de verdade e objetividade aos números e seus efeitos de seleção e classificação é querer esconder e abafar o fato de que o campo social é penetrado de valores, interesses e conflitos. É esse caráter ético e, portanto, político que coloca a avaliação no centro das reformas e dos conflitos, pois o que está em jogo e em disputa é o modelo de sociedade (DIAS SOBRINHO, 2004, p. 722).

Em meio às distintas orientações de modelos avaliativos, se desdobram a defesa de distintas concepções de educação e de sua qualidade, uma 12 vez que se entende que é necessário definir algumas referências e objetivos que desvelam um ideal de educação para avaliar, o que coloca a concepção de qualidade educacional como um campo de disputa pela não neutralidade em sua configuração.

Esta análise parte da defesa da educação como formação humana com objetivo do desenvolvimento pleno e emancipatório de todos os cidadãos, para suscitar uma vida em sociedade mais justa que se configura como direito, entendendo que ter boa qualidade é condição de sua efetivação.

Assim como afirma Almeida (2014), há fatores internos e externos às escolas que impactam na qualidade educacional. Inserir a educação num rol de direitos sociais, implica em defender que a qualidade educacional está atrelada à qualidade de condições de vida e ao compartilhamento de bens materiais, simbólicos e sociais.

Bertagna (2017) também reforça esses importantes aspectos sociais da educação como fator de formação humana para o desenvolvimento pleno das pessoas. A autora apresenta a proposta de ampliação das dimensões da qualidade para promover a formação humana emancipatória, a saber: 
político-social, ética, afetiva, corporal, cognitiva, artística e cultural, considerando que são os processos de Avaliação Institucional Participativa (AIP) que permitem alçar os elementos para sua efetivação.

Consideramos que as ações cotidianas que constituem os processos educacionais têm potenciais para estagnar ou modificar as relações e as formações humanas. Ou seja, pode-se tomar a organização da escola e dos sistemas de ensino de forma a intensificar modelos autoritários, hierárquicos e excludentes, ou os transformar em modelos cada vez mais democráticos, inclusivos e justos.

Mello e Bertagna (2016) apresentam análise de dados relativos ao IDEB, às taxas de analfabetismo, ao produto interno bruto per capita, ao produto interno bruto (PIB) e ao índice de desenvolvimento humano (IDH) dos estados brasileiros para incitar a reflexão/problematização sobre os múltiplos fatores da qualidade educacional, o que requer políticas públicas efetivas para obter melhoria um desenvolvimento amplo e estrutural. As autoras verificam que, embora não se trate de relações lineares, os fatores sociais e econômicos dos estudantes impactam nas possibilidades educacionais.

Por outro lado, sabemos que interesses econômicos e políticos de perspectiva neoliberal conduzem ao entendimento de qualidade educacional de forma meritocrática, favorecendo apenas alguns grupos sociais. Os discursos pautados na meritocracia ensejam que considerar as implicações sociais e econômicas da vida dos estudantes na análise educacional consiste em disputa ideológica e não na configuração da qualidade em educação, como se a análise quantitativa de desempenho fosse uma perspectiva neutra.

Tomemos como análise a ideia de eficiência difundida desde a Reforma Administrativa do Estado Brasileiro, oficializada no primeiro governo do PSDB (1995-1998) e apontada como justificativa para implementar a reforma, que também afetou a organização e a oferta pública de educação.

Analisando o termo eficiência, a partir das considerações de Lima (1997), observa-se que sua orientação se volta mais para a ideia de consumidores (orientação de mercado) do que para os cidadãos (orientação cívica), estabelecendo uma relação de competência, produtividade e rendimento. Assim sendo, versar sobre o avanço da eficiência do serviço público alude a refletir sobre um determinado padrão de qualidade, portanto, faz-se relevante 
Tensões do SAEB e do IDEB para a educação de qualidade como direito

destacar diferentes concepções de qualidade educacional e apontá-la como condição à garantia do direito à educação.

Entendemos que é necessário ter uma perspectiva multidimensional e promover ações estratégicas para que se atinja uma qualidade educacional socialmente referenciada. Como apontam Sordi; Oliveira; Silva; Bertagna e Dalben:

[...] o que inclui a defesa de uma avaliação de larga escala multidimensional capaz de articular dimensões que as atuais políticas deixam renegadas e esquecidas, tais como: a dos valores, das aprendizagens colaborativas, dos sentidos da cidadania, do respeito à diversidade e à tolerância, entre outros. (SORDI; OLIVEIRA; SILVA; BERTAGNA; DALBEN, 2016, p. 7211.

Qualidade também se relaciona com o tempo histórico, com as visões de mundo, e com os objetivos educacionais traçados. Como reforça Almeida:

[...] quando ouvimos a expressão qualidade educacional ela pode: remeter à formação de uma elite pensante adequada aos preceitos educacionais de uma parte da população; estar vinculada à ideia de capital humano e preparação de mão de obra para o mercado; se relacionar à preparação para o vestibular demandada principalmente pela classe média; significar a pretensão de formação crítica dos educandos como vislumbrado por muitos movimentos sociais; se voltar à busca de índices que possibilitem o enquadramento no chamado 'nível básico' medido a partir da adoção de testes padronizados; significar o rompimento com a instituição escolar como a conhecemos hoje, dando espaço a uma nova organização em que a vida é novamente o cerne mobilizador da relação ensino aprendizagem... Enfim, falar em qualidade educacional pode nos remeter a diversos significados em dependência do contexto a que se refere e das concepções às quais se vincula (ALMEIDA, 2014, p. 52).

Dessa forma, não se busca aqui mencionar um padrão de qualidade minuciosamente delineado, mas propor uma reflexão sobre a amplitude dessa conceituação frente à defesa da educação para formação humana como direito social que deve ser garantido pelo poder público.

No processo histórico, observamos que inicialmente os estados se pautaram na ideia de qualidade com base na expansão da oferta educacional, 
muitas vezes, desarticulada da preocupação com as condições dessa oferta, ainda que se saiba que o componente quantitativo de acesso é parte importante de sua configuração.

Considerando a crescente ênfase nos sistemas avaliativos em nível mundial como medida de qualidade, é perceptível a adesão à cultura avaliativa (DIAS SOBRINHO, 2004) e a aceitação da medida como expressão de qualidade. O questionamento dessa aceitação encontra posicionamentos políticos contrários à regulação métrica da educação - ou educação contábil, conforme Lima (1 997) -frente aos preceitos neoliberais, mesmo que o consenso da necessidade de avaliar tenha se tornado "[...] difícil desmontar e pôr em questão a sua aparente e pretendida neutralidade" (AFONSO, 2007, p. 17).

Um dos problemas gerados por esse consenso é que a avaliação foi enfatizada de tal forma que se tornou um objetivo em si, emergindo como finalidade da educação formal (escolar), sem espaços para o debate dos aspectos formativos e das intencionalidades pedagógicas. Avaliar deve incluir processos de investigação e de retomadas, no caso das avaliações de sistema e das políticas públicas educacionais, para garantir a qualidade educacional a todos com participação democrática dos cidadãos.

No entanto, com a evidência do modelo gerencial da educação, a qualidade total foi transposta aos sistemas educacionais. Com base em Gentili (1995), compreendemos que essa qualidade, que tem base neoliberal, exalta o mercado como a única garantia de liberdade e progresso para a sociedade, incitando a competição como sua promotora. Nessa perspectiva, caracteriza a educação como mercadoria, cobra produtividade dos atores sociais com base em resultados mensuráveis para efetivar uma gestão considerada eficiente, ponderada a partir do avanço nos resultados e redução dos custos educacionais. As avaliações padronizadas surgem como uma forma de controle estatístico da qualidade na busca pela diminuição dos desperdícios. Essa perspectiva de qualidade é questionável:

[...] o discurso da qualidade foi (e continua a ser frequentemente) um discurso redutor quando se baseia apenas numa racionalidade instrumental que tende a sobrevalorizar indicadores e resultados quantificáveis sem levar em conta as políticas educacionais, os sujeitos e os respectivos processos e contextos educativos. Neste sentido, a chamada avaliação da qualidade da educação tem significado, sobretudo, uma estratégia para levar a cabo uma certa 
Tensões do SAEB e do IDEB para a educação de qualidade como direito

(re)meritocratização e elitização do sistema educativo, com o consequente aumento da selectividade social (AFONSO, 2007, p. 18).

Bentancur (2008) destaca a influência de organismos financeiros internacionais e apresenta que a qualidade passou a ser um conceito que ganha evidência na organização da retórica reformista. $\bigcirc$ autor destaca que se trata de uma qualidade associada a

[...] la formación de individuos en competencias definidas, en función de los parámetros del mercado de empleo y consumo. [...] El pasaje de los valores de ciudadanía y solidaridad social a los de competencia y eficiencia deja un vacío, pues mientras los dos primeros habilitan el desarrollo de sentido de pertenencia, los segundos lo erosionan (BENTANCUR, 2008, p. 68).

Dessa forma, a limitação ao modelo formativo para continuidade de uma organização social desigual e injusta inibe o potencial da escola em promover a democracia, a autonomia dos atores, o senso coletivo e crítico, entre outros elementos que não são medidos nas avaliações padronizadas.

Sousa (2014) aponta que as avaliações de sistema em larga escala têm forjado a concepção de qualidade, ou seja, implicam na assimilação de que a qualidade é apresentada pelos resultados obtidos. Forjar é esconder as condições reais da educação para apontar que há melhorias da qualidade quando os índices se elevam, uma vez que as condições de oferta educacional e de trabalho docente são as mesmas. E também desconsiderar que a pressão por resultados gera estratégias para alcançar as metas impostas, o que, como se vê em Freitas (2012), não condiz com a efetiva qualidade. Sousa destaca que, no Brasil, a ênfase nestas avaliações

[...] revelam a crença dos formuladores das políticas educacionais de que os testes têm se constituído em meio promissor da melhoria da qualidade do ensino. Ficam as questões: aplicar mais provas é uma resposta ou, melhor, é uma solução para aprimorar o desempenho dos estudantes nas provas? Ou, ainda, as avaliações em larga escala têm propiciado a melhoria da qualidade da educação? Ao longo dos quase 25 anos de aplicação do SAEB as evidências trazidas não nos autorizam a uma resposta positiva a estas questões (SOUSA, 2014, p. 411 ). 
A aprovação da Lei n 13.005/2014, que institui o Plano Nacional de Educação (PNE) 20 14-2024 (BRASIL, 20 14), vem, mais uma vez, reforçar os resultados do IDEB como parâmetro para verificar a qualidade da educação brasileira. Como ressaltam Filipe e Bertagna (2015), esse parâmetro se assenta em princípios mercadológicos, com repasse da responsabilidade estatal com a qualidade educacional para a esfera privada, marcando um retrocesso na garantia desse direito e minimizando as potencialidades para a construção da qualidade social.

Desse modo, se entende que as políticas públicas atuais estão enviesadas pelo poder do sistema econômico, seguindo os ditames do empresariado sem de fato minimizar as desigualdades de resultados educacionais com desenvolvimento das condições dos sistemas de ensino público.

$\bigcirc$ trabalho dos professores acaba sofrendo com a meritocracia, já que os melhores professores podem ser motivados a buscar maior rendimento (bônus salarial atrelado aos resultados de desempenho dos estudantes) ao invés de uma melhor formação para os alunos e condição de trabalho dos profissionais da educação, e ainda podem ser desmoralizados publicamente pelas sanções ou premiações resultantes das avaliações realizadas. Freitas (2012) mostra que a meritocracia não tem impacto no desempenho dos estudantes, mas implica em graves consequências para a educação, como individualismo, competição, entre outros.

É nesse ponto que se debruça nossa preocupação: a avaliação meritocrática de desempenhos implica na aceitação de que ter uma educação de qualidade depende única e exclusivamente de mérito pessoal, que não se configuraria em um compromisso estatal com a garantia desse direito.

Compreendemos que olhar apenas para resultados em testes cognitivos determina uma perspectiva limitada de educação de qualidade, não só em relação ao próprio recorte, mas também ao reduzido número de unidades escolares que apresentam resultados elevados. Além do sistema educacional, o fato de que muitas vezes as avaliações alcançam os melhores resultados entre os estudantes com maior capital cultural, econômico e social (BOURDIEU, 1998) evidencia que estes nem sempre são eficientes (ALMEIDA; DALBEN; FREITAS, 2013) e que o sistema atende de forma desigual com condições de acesso e permanência igualmente desiguais. 
Entendendo a necessidade da educação de qualidade social ISILVA, 2009), devem ser respeitados os aspectos que se referem à estrutura física apropriada, com segurança, limpeza e espaço amplo; formação docente em nível superior e constante atualização; valorização dos profissionais da educação com remuneração e condições de trabalho adequadas; proposta pedagógica que respeite o desenvolvimento do aluno, com proposta de estimular a apropriação da cultura e os conhecimentos historicamente construídos em um processo emancipatório; recursos materiais e financeiros coerentes com as demandas de atendimento e com os projetos pedagógicos; gestão democrática; promoção de valores éticos e políticos que primem pela justiça e igualdade; condições de vida dos atores sociais; entre outros. Sem a pretensão de fechar o conceito de qualidade nos aspectos elencados, destacamos uma questão principal: a coerência entre investimento financeiro e democratização no tratamento da questão da qualidade.

A partir dos questionamentos aqui expostos e outras perspectivas que podem ter suscitado, destacamos a necessidade de considerar conceitos mais amplos e democráticos de qualidade para elaboração das políticas educacionais no Brasil.

\section{Para não finalizar: algumas provocações que nos levam a caminhar em defesa da educação pública de qualidade}

O SAEB e o IDEB, enquanto políticas de avaliação dos sistemas de ensino no Brasil, são instrumentos que apontam resultados quantitativos sobre a educação. Esses resultados têm sido apresentados nos documentos oficiais como indicativos da qualidade. No entanto, tensionando o conceito de qualidade proposto com a sua contextualização em uma sociedade desigual, entendemos que quando se relaciona a ideia de mérito com a conquista de metas e se foca nos desempenhos dos estudantes apenas em linguagem e matemática, há um estreitamento do direito à educação de qualidade tanto em seu objetivo - qual seja, garantir habilidades e competências nas áreas mencionadas - quanto em sua efetivação, porque há unidades e redes de ensino com baixo desempenho devido às condições em que se encontram. Elas necessitam de políticas de apoio para avançar, não basta inseri-las na competição. 
Tal contexto impulsiona e incentiva a competição no campo educacional que busca apresentar melhores resultados com a disseminação de relações sociais individualistas e organizações hierárquicas, fazendo com que a classe popular se conforme com discursos e ações políticas que não a contemple. Ou seja, ao invés de promover uma cooperação para que todos os estudantes brasileiros recebam educação de qualidade, independentemente de sua origem, somente se enaltece que a qualidade está presente em unidades e redes de ensino que se mostram mais eficientes dentro da lógica da competição.

Realçamos que recorrer somente às metas do IDEB e aos resultados dos testes do SAEB para considerar a qualidade educacional sem aprofundar a análise de fatores intra e extraescolares, assim como sem considerar dimensões formativas mais amplas, pode acarretar a responsabilização por resultados insatisfatórios (que não atinjam as metas estabelecidas) somente aos professores, aos gestores da unidade escolar, aos estudantes e suas famílias sem contemplar todo do processo educacional.

Compreendemos que tais políticas avaliativas se acercam aos princípios meritocráticos e individualistas, por priorizar os resultados de desempenho em testes, culpabilizam a comunidade escolar por esses resultados e, ainda, destacam alguns casos de "sucesso", muito embora o resultado aponte somente para o que Freitas (2004) assinalou como a qualidade possível à classe trabalhadora. De tal forma, não se configuram como ações estatais efetivas para garantir o suporte necessário à igualdade de acesso, de permanência e de apropriação do conhecimento, logo, não caminham para efetivar democraticamente a qualidade educacional.

Antes que se entenda as críticas ora apresentadas como oposição à avaliação externa, reiteramos a sua importância. No entanto, compreendemos que modelos amostrais e articulados com processos participativos, como os propostos pelas AIPs, se apresentam como profícuas possibilidades para abarcar as dimensões de qualidade social da educação e promover a responsabilização bilateral entre o Estado e a escola.

Consideramos que se faz importante lutar pelo compromisso do poder público com o direito à educação de qualidade à toda população, requerendo a reformulação dos processos avaliativos atuais para que se pautem na conceitualização da qualidade social da educação e considerem suas 
multidimensões. Além disso, que promova políticas públicas educacionais que consubstanciem a garantia desse direito.

\section{Notas}

$1 \bigcirc$ INEP, por meio da Portaria $n^{\circ}$ 69, de 4 de maio de 2005, estabeleceu que seriam avaliadas todas as escolas da zona urbana com 30 alunos matriculados em cada uma das etapas avaliadas.

\section{Referências}

AFONSO, Almerindo Janela. Estado, políticas educacionais e obsessão avaliativa. Contrapontos, Itajaí, v. 7, n. 1, p. 1 1-22, jan./abr. 2007.

AFONSO, Almerindo Janela. Nem tudo o que conta em educação é mensurável ou comparável: crítica à accountability baseada em testes estandardizados e rankings escolares. Revista Lusófona de Educação, Lisboa, n. 13, p. 13-29, 2009.

20 ALMEIDA, Luana Costa. Relação entre o desempenho e o entorno social em escolas municipais de Campinas: a voz dos sujeitos. 2014. 325f. Tese (Doutorado em Educação) Programa de Pós-Graduação em Educação, Universidade Estadual de Campinas, Campinas, 2014.

ALMEIDA, Luana Costa; DALBEN, Adilson; FREITAS, Luiz Carlos. O ldeb: limites e ilusões de uma política educacional. Educação e Sociedade, Campinas, v. 34, n. 125, 2013.

BAUER, Adriana; SOUSA, Sandra Zakia Lian; HORTA NETO, João Luiz; VALLE, Raquel da Cunha; PIMENTA, Cláudia Oliveira. Iniciativas de avaliação do ensino fundamental em municípios brasileiros: mapeamento e tendências. Revista Brasileira de Educação, Rio de Janeiro, v. 22, n. 71, 2017.

BENTANCUR, Nicolas. Las reformas educativas de los años noventa en Argentina, Chile y Uruguay: racionalidad política, impactos y legados para la agenda actual. Montevideo: Ediciones de la Banda Oriental, 2008.

BERTAGNA, Regiane Helena. Dimensões da formação humana e qualidade social: referência para os processos avaliativos participativos. In: SORDI, Mara Regina Lemes de; VARANI, Adriana; MENDES, Geisa do Socorro Cavalcanti Vaz (org.). Qualidade(s) da escola pública: reinventando a avaliação como resistência. Uberlândia: Navegando Publicações, 2017. 
BERTAGNA, Regiane Helena; BORGHI, Raquel Fontes. Sistemas de avaliação dos estados no Brasil: avanços do gerencialismo na educação básica. Revista Teias, Rio de Janeiro, v. 19 , n. 54, jul./set. 2018.

BLOOM, Benjamin Samuel. Taxionomia de objetivos educacionais. Porto Alegre: Globo, 1972.

BOURDIEU, Pierre. Capital cultural. In: NOGUEIRA, Maria Alice; CATANI, Afrânio (org.). Escritos de educação. 8. ed. Petrópolis: Vozes, 1998.

BRASIL. Constituição da República Federativa do Brasil. Diário Oficial da União, Brasília, DF, 5 out. 1988, n 191-A, p. 1, Seçãol.

BRASIL. Lei n 9.394, de 20 de dezembro de 1996. Dispõe sobre as Diretrizes e Bases da Educação Nacional. Diário Oficial da União, Brasília, DF, 23 dez, 1996.

BRASIL. Lei n 13.005, de 25 de junho de 2014. Aprova o Plano Nacional de Educação PNE e dá outras providências. Diário Oficial da União, Brasília, DF, 26 jun. 2014.

BRASIL. Ministério da Educação. Decreto n 6.094, de 24 de abril de 2007. Implementação do Plano de Metas Compromisso Todos pela Educação. Brasília: MEC, 2007. Disponível em: http://www.planalto.gov.br/ccivil_03/_Ato2007-2010/2007/Decreto/D6094. htm. Acesso em: 20 abr. 2020.

BRASIL. Ministério da Educação. Portaria n 366, de 29 de abril de 2019. Estabelece as diretrizes de realização do Sistema de Avaliação da Educação Básica (SAEB) no ano de 2019. Diário Oficial da União, Brasília, DF, 2 maio 2019, p. 47, edição, 83, Seçãol.

BROOKE, Nigel; CUNHA, Maria Amália; FALEIROS, Matheus. A avaliação externa como instrumento da gestão educacional nos estados: relatório final. Belo Horizonte: Game/ Editora UFMG/Fundação Victor Civita, 2011.

DIAS SOBRINHO, João. Avaliação ética e política em função da educação como direito público ou como mercadoria? Educação \& Sociedade, Campinas, v. 25, n. 88, p. 703725, out. 2004 .

FERNANDES, Reynaldo. Índice de Desenvolvimento da Educação Básica (Ideb). Brasília: Instituto Nacional de Estudos e Pesquisas Educacionais Anísio Teixeira, 2007.

FILIPE, Fabiana Alvarenga; BERTAGNA, Regiane Helena. Avaliação e qualidade no novo Plano Nacional de Educação: avanços e possíveis retrocessos? EccoS, São Paulo, n. 36, p. 49-66, jan./abr. 2015. 
FREITAS, Luiz Carlos; SORDI, Mara Regina Lemes de; MALAVASI, Maria Marcia Sigrist; FREITAS, Helena Costa Lopes de. Avaliação Educacional: caminhando pela contramão. 4. ed. São Paulo: Vozes, 2012.

FREITAS, Luiz Carlos. A avaliação e as reformas dos anos de 1990: novas formas de exclusão, velhas formas de subordinação. Educação \& Sociedade, Campinas, v. 25, n. 86, p. $131-170,2004$.

FREITAS, Luiz Carlos. Eliminação adiada: o ocaso das classes populares no interior da escola e a ocultação da (má) qualidade do ensino. Educação \& Sociedade, Campinas, v. 28, n. 100, p. 965-987, out. 2007.

FREITAS, Luiz Carlos. Os reformadores empresariais da educação: da desmoralização do magistério à destruição do sistema público de educação. Educação \& Sociedade, Campinas, v. 33, n. 119 , p. 379-404, abr./jun. 2012.

GENTILI, Pablo. O discurso da "qualidade" como nova retórica conservadora no campo educacional. In: GENTILI, Pablo; SILVA, Tomaz Tadeu (org.). Neoliberalismo, qualidade total e educação. Petrópolis: Vozes, 1995;

HORTA NETO, João Luiz. As avaliações externas e seus efeitos sobre as políticas educacionais: uma análise comparada entre a União e os estados de Minas Gerais e São Paulo. 2013. 358 f. Tese (Doutorado em Política Social) - Programa de Pós-Graduação em Política Social. Universidade de Brasília, Brasília, 2013.

INSTITUTO NACIONAL DE ESTUDOS E PESQUISAS EDUCACIONAIS ANISIO TEIXEIRA (INEP). Saeb. Aneb e Anresc (Prova Brasil). Menu do gestor. Objetivos das avaliações. Brasilia: Inep, 2011.

INSTITUTO NACIONAL DE ESTUDOS E PESQUISAS EDUCACIONAIS ANÍSIO TEIXEIRA (INEP). Cartilha SAEB 2019. Brasilia: Inep, 2019.

INSTITUTO NACIONAL DE ESTUDOS E PESQUISAS EDUCACIONAIS ANÍSIO TEIXEIRA (INEP). Portaria $\mathbf{n}^{\circ} \mathbf{2 7 1}$, de $\mathbf{2 2}$ de março de 2019. Estabelece as diretrizes de realização do Sistema de Avaliação da Educação Básica (SAEB) no ano de 2019. Diário Oficial da União, Brasília, DF 25 março 2019, p. 59. edição 57, seção 1.

INSTITUTO NACIONAL DE ESTUDOS E PESQUISAS EDUCACIONAIS ANÍSIO TEIXEIRA (INEP). Educação Básica. Ideb. Brasília: Inep, 2020. 
LIMA, Licínio Carlos. $\bigcirc$ paradigma da educação contábil. Políticas educativas e perspectivas gerencialistas no ensino superior em Portugal. Revista Brasileira de Educação, Rio de Janeiro, n. 4, jan-abr. 1997.

MELLO, Liliane Ribeiro de; BERTAGNA, Regiane Helena. Apontamentos iniciais sobre qualidade educacional: resultados do IDEB e fatores socioeconômicos. Revista Ibero-Americana de Estudos em Educação, Araraquara, v. 11, p. $1132-1148,2016$.

RAPHAEL, Hélia Sonia. Avaliação: questão técnica ou política? Revista Estudos em Avaliação Educacional, São Paulo, n. 12, p. 33-44, jul./dez. 1995.

SILVA, Maria Abadia. Qualidade social da educação pública: algumas aproximações. Cadernos Cedes, Campinas, v. 29, n. 78, p. 21 6-226, maio/ago. 2009.

SORDI, Mara Regina Lemes de; OlIVEIRA, Sara Brada; SILVA, Margarida; BERTAGNA, Regiane Helena; DALBEN, Adilson. Indicadores de qualidade social da escola pública: avançando no campo avaliativo. Estudos em Avaliação Educacional, São Paulo, v. 27, n. 66, p. 716-753, set./dez. 2016.

SOUSA, Sandra Zakia Lian. Concepções de qualidade da educação básica forjadas por meio de avaliações em larga escala. Avaliação, Campinas, Sorocaba, v. 19, n. 2, p. 407 420, jul. 2014.

VIANNA, Heraldo Marelim. Avaliação do rendimento de alunos de escolas de $1^{\circ}$ grau da rede pública: uma aplicação experimental em 10 cidades. Educação e Seleção, São Paulo, n. 17, p. 6-52, 1988.

Ms. Liliane Ribeiro de Mello

Universidade Estadual Paulista (Brasil) Doutoranda do Programa de Pós-Graduação em Educação (UNESP/Rio Claro) Grupo de Estudos e Pesquisas em Política Educacional (GREPPE) Orcid id: https:/ / orcid.org/0000-000 1-7263-7922 E-mail: liliane.mello@unesp.br 
Artigo

Tensões do SAEB e do IDEB para a educação de qualidade como direito

Profa. Dra. Regiane Helena Bertagna

Universidade Estadual Paulista (Brasil)

Programa de Pós Graduação em Educação

Departamento de Educação (UNESP/Rio Claro)

Vice-líder do Grupo de Estudos e Pesquisas em Política Educacional (GREPPE)

Orcid id: https: / / orcid.org/0000-0003-44 1 5-0978

E-mail: regiane.bertagna@unesp.br

Recebido 18 maio 2020

Aceito 15 ago. 2020 